\title{
LA SUPREMA CORTE COMO TRIBUNAL CONSTITUCIONAL: ¿EL INEVITABLE ACERCAMIENTO DE LA FUNCIÓN JURISDICCIONAL A LA POLÍTICA?
}

\author{
Everardo RODRÍGUEZ DURÓN
}

\begin{abstract}
No hay razón para atribuir a ningún otro grupo determinado una mejor capacidad para la argumentación moral; o si la hay, entonces lo que hay que cambiar es el proceso de selección de los jueces, no las técnicas para juzgar que se les pide que usen. De manera que esta forma de escepticismo no es en sí misma un argumento en contra de la técnica de adjudicación de Hércules, por más que ciertamente sirva como oportuno recordatorio, para cualquier juez, de que bien puede equivocarse en sus juicios políticos y de que, por ende, ha de decidir con humildad los casos difíciles.
\end{abstract}

Ronald DwORKIN, Los derechos en serio

Sumario:

I. Preliminares II. Algo más sobre el Estado constitucional III. ¿La politización de la justicia o la judicialización de la política? IV. La Suprema Corte como Tribunal Constitucional V. Las influencias de la política en la función judicial VI. ¿De camino al gobierno de los jueces? VII. A manera de conclusión VIII. Fuentes empleadas

Resumen: En este artículo me propongo explorar las implicaciones que tiene para el sistema jurídico la aceptación de la función de la Suprema Corte como Tribunal Constitucional. En los apartados siguientes analizaré una serie de aspectos que me parece constituyen los presupuestos y las consecuencias de esta nueva concepción de las cortes constitucionales no solo como legisladores negativos, sino como instancias comprometidas con el cambio social. Finalizaré el estudio con un breve argumento sobre la forma en la que es posible superar la objeción democrática que pesa sobre la justicia constitucional.

Palabras Clave: Constitución, onstitucionalismo, cortes constitucionales, derechos fundamentales, gobierno de los jueces, bjeción contramayoritaria, positivismo jurídico.

\footnotetext{
${ }^{1}$ Licenciado en Derecho por la Universidad Autónoma de Aguascalientes y maestro en Justicia Constitucional por la Universidad de Guanajuato. contacto: everardord@hotmail.com. Agradezco al Dr. Francisco M. MoRA Sifuentes, los pertinentes comentarios y observaciones que me realizó durante el proceso de redacción de este texto, así como respecto de la versión definitiva.
} 
Abstract: In this paper I propose to explore the implications for the legal system of the acceptance of the role of the Supreme Court as a Constitutional Court. In the following sections I will analyze a series of aspects that I believe constitute the assumptions and consequences of this new conception of the constitutional courts not only as negative legislators, but as instances committed to social change. I will finish the study with a brief argument on the way in which it is possible to overcome the democratic objection that weighs on constitutional justice.

Keywords: Constitution, constitutionalism, constitutional courts, fundamental rights, government of judges, countermajoritarian objection, legal positivism.

\section{Preliminares}

En el presente texto me propongo explorar un conjunto de tesis que, aunque ya han sido analizadas por la literatura especializada, no dejan de tener interés para la doctrina. En síntesis, me referiré a la actividad de las cortes constitucionales como entes controladores del resto de los poderes públicos, lo que implica que los colegios judiciales ejerciten un novedoso elenco de facultades jurisdiccionales sobre todo en lo que mira a la declaración de inconstitucionalidad de la ley. No quiero decir con ello, por ejemplo, que las cortes constitucionales no hayan ejercido antes funciones semejantes; pero me parece que en la actualidad el control judicial de constitucionalidad ha adquirido una notoria trascendencia cuando se le estudia inserto en un escenario más complejo como el proporcionado por las constituciones rígidas y rematerializadas, gracias al reposicionamiento de los derechos fundamentales como parámetros de validez objetiva ${ }^{2}$, aunado a que las propias cortes han asumido un papel creativo dentro del ordenamiento, lo que las aleja del modelo ortodoxo preconizado por la posición kelseniana del legislador negativo ${ }^{3}$.

En esencia, me parece que nuestra Suprema Corte no escapa de la fisonomía de un tribunal constitucional, tanto por la depuración competencial que en las últimas décadas se ha realizado sobre las atribuciones que en materia de control de legalidad, que ahora son conocidas por los órganos judiciales inferiores; como por el hecho de que el propio alto tribunal ha asumido un discurso judicial que tienen como punto de partida fundamental, la imagen que la propia Corte tiene de sí misma como tribunal materialmente constitucional ${ }^{4}$. Por eso, en esta contribución me detendré, primero, a reflexionar sobre el que me parece es el presupuesto teórico desencadenante de la novedosa función que desempeña la Corte como intérprete final de la Constitución. Al parecer, este presupuesto no es otro que la aparición, hacia la segunda mitad del siglo pasado, del Estado constitucional. En segundo término, me referiré a los diversos modelos que, a lo

\footnotetext{
${ }^{2}$ Sobre la función objetiva de los derechos fundamentales, me remito al reciente trabajo de Mora Sifuentes, Francisco M. (2017), La influencia de los derechos fundamentales en el ordenamiento. Su dimensión objetiva, en Boletín Mexicano de Derecho Comparado, No. 150, México, IIJ/UNAM, pp. 1222-1231.

3 Tal era la función que según KELSEN les correspondía desempeñar a las cortes constitucionales a través de la depuración de las normas irregulares. Sobre esta cuestión, me remito al clásico estudio de KelSEN, Hans, La garantía jurisdiccional de la constitución (La justicia constitucional), trad. de Rolando TAMAYo y SALMORÁN, México, IIJ/UNAM, 2001, pp. 52-54. Un estudio más detallado sobre el argumento kelseniano se puede ver en Rodríguez Durón, Everardo, El control constitucional ante el desafío democrático. Un acercamiento al problema contramayoritario en el derecho constitucional mexicano, Tesis para obtener el grado de Maestro en Justicia Constitucional, Universidad de Guanajuato, Guanajuato, 2017, pp. 101-110. En todo caso, sobre este aspecto volveré más adelante, dentro de este mismo estudio.

${ }^{4}$ Los efectos que ha tenido la aceptación de la función de la Suprema Corte como tribunal constitucional, se pueden ver en Cossío Díaz, José Ramón (2013), Sistemas y modelos de control constitucional en México, $2^{\mathrm{a}}$ edición, México, IIJ/UNAM, pp. 136-172.
} 
largo de la historia, se han ideado para garantizar la observancia de los mandatos constitucionales 5 . Este repaso evidenciará que, si bien no existe una vinculación conceptual entre el constitucionalismo contemporáneo y el control judicial, si existe una tendencia determinante para ver a estos dos fenómenos como cuestiones mutuamente imbricadas. Esta vinculación (contingente) explica la forma en que el control de regularidad de las normas y actos de la autoridad, se fue decantando hasta crear una jurisdicción especializada que se depositó en manos de los tribunales constitucionales. La existencia de una jurisdicción especializada para resolver en definitiva las cuestiones donde está implícita la interpretación de las normas constitucionales, y la dilucidación, por último, de los derechos que tenemos, describe un nuevo enclave institucional a través del cual debe ser entendida la relación -tirante o deferente- entre el poder político y la magistratura constitucional. Desde luego, dicha cuestión no es más que el reposicionamiento de la objeción contramayoritaria que aqueja a la justicia constitucional desde su origen, pero que, en el contexto presente, reclama una nueva centralidad y mejores argumentos para compatibilizar las exigencias democráticas con la presencia de una rama judicial que puede dar contra a las determinaciones tomadas con base en la regla de la mayoría. A estas alturas, el lector podrá haberse percatado de que tomadas individualmente ninguna de estas afirmaciones nos dice cosas nuevas; sin embargo, también podrá advertir que es el conjunto de todas ellas lo que destaca. En efecto, se trata de un grupo de tesis que tomadas en conjunto nos proporcionan elementos adecuados para explicarnos el papel que los tribunales constitucionales desempeñan en nuestras democracias; y en especial, por lo que hace a la función institucional de nuestra Suprema Corte.

Con estas aclaraciones podemos comenzar nuestro estudio de naturaleza descriptiva sobre el acercamiento de la función judicial a la política. En ese sentido, me parece pertinente dejar en claro que en lo que sigue lo único que sostengo es que, dadas las condiciones actuales derivadas del paradigma constitucional, el poder judicial se convierte también en un instrumento de cambio y crítica interna del Derecho. Ello no quiere decir que antes no fuese así, pero lo que no debe perderse dentro de este desarrollo es que la actividad de la jurisdicción constitucional es también un medio útil para concretar los efectos de la dimensión objetiva de los derechos dentro de nuestro sistema, en una forma tan eficaz, que la Corte se ha convertido también en un instrumento de cambio social.

\section{Algo más sobre el Estado constitucional}

Cualquier contenido puede ser derecho ${ }^{6}$, con esta afirmación tantas veces citada, la teoría pura resumió su pretensión para construir una ciencia del derecho axiológicamente neutra y únicamente descriptiva de su objeto. Para ello tomó como presupuesto necesario la separación conceptual entre el derecho y la moral ${ }^{7}$, de suerte que concibió a aquél como un sistema de normas identificables a través de los criterios formales establecidos en un conjunto de preceptos de carácter superior encargados de determinar los procesos formales para la creación y la aplicación jurídica ${ }^{8}$. El positivismo conceptualiza al derecho como un sistema de reglas preestablecidas

\footnotetext{
${ }^{5}$ El tema de los modelos de control constitucional es tratado de forma adecuada en Tusseau, Guillaume (2011), Para acabar con los modelos de jurisdicción constitucional. Un ensayo de crítica, trad. de Teresa García Berrio, México, Porrúa-IMDPC, texto al cual sigo en esta parte.

${ }^{6}$ Kelsen, Hans (2005), Teoría pura del derecho, trad. de Roberto Vernengo, 14a edición, México, Porrúa, p. 205.

${ }^{7}$ Alexy, Robert (2005), Derecho y moral, en Ferrer MaC-Gregor, Eduardo (coordinador) Interpretación constitucional, México, Porrúa-IIJ/UNAM, tomo I, p. 1.

${ }^{8} \mathrm{RAz}$ se refiere a esta cuestión a través de la idea de las cadenas de validez; para este autor una cadena de validez es un conjunto de todas aquellas normas tales que: (1) cada una de ellas autoriza, precisamente, la creación de una
} 
y considera que el fundamento de validez de las normas y actos concretos de aplicación son válidos en cuento pueden inferirse de normas superiores hasta llegar a una norma superior, de la cual no puede predicarse su validez como norma puesta, sino que opera únicamente como hipótesis de trabajo para los juristas ${ }^{9}$. En este sentido, aunque la teoría pura reconoce que el juez crea derecho en la medida en que la sentencia judicial es una norma jurídica individualizada ${ }^{10}$, lo cierto es que el positivismo se limitó a reconocer el ejercicio de la discrecionalidad del juez en los casos donde es difícil determinar si el supuesto cae en la zona de aplicación de una disposición o, bien se ubican fuera del ámbito regulado por la norma de que se trate. Por ahora, con esta descripción es suficiente para resaltar el punto que me interesa en este momento, pues si bien el positivismo aportó una lectura adecuada que permitió centrar a la jurisprudencia como una ciencia con presupuestos perfectamente determinados; también es verdad que se concentró poco en desarrollar una teoría de la argumentación jurídica que permitiera explicar de mejor manera la forma en la que razonan los jueces. Del mismo modo, también se ocupó de aportar una imagen mecánica de la función de las cortes constitucionales en la medida en que limitó su función a la depuración del ordenamiento.

Este estado de cosas cambio después de la Segunda Guerra Mundial, precisamente en el momento en que, con tal de superar los horrores del holocausto, los juristas se ocuparon de reflexionar sobre la forma adecuada de acercarse al conocimiento de su objeto de estudio a fin de que el derecho se definiera también por la recepción de ciertos contenidos valorativos. Los juicios de Núremberg dan cuenta de que no siempre el derecho válido es el que ha resultado de los procesos formales determinados en las normas sobre producción jurídica; sino que el contenido de las disposiciones también es importante para que una norma sea tal. La aceptación de este hecho no significa el ocaso de la tesis de la separación entre el derecho y la moral, sino únicamente una flexibilización de los presupuestos sobre los que se asienta el positivismo. Es decir, es una cuestión de hecho que en ocasiones las exigencias del derecho coinciden con los imperativos de la moralidad. Si la tesis de la separación se entiende de esta forma, el positivismo como manera de acercarse al derecho es todavía un enfoque adecuado para explicar el advenimiento del constitucionalismo. Por ejemplo, existe una norma moral que me ordena respetar a mis padres; pero también un mandamiento religioso me impone tal deber, y no es extraño que una norma jurídica me depare una obligación semejante. El ámbito de las tres normas se superpone al definir la conducta que debo observar, pero de ello no se sigue que siempre deba existir una vinculación entre los tres ámbitos, ni que el derecho deba definirse por referencia a la moral. Así como la recepción de ciertas normas de derecho internacional privado posibilita que las mismas puedan aplicarse por los jueces nacionales sin pertenecer al sistema jurídico, lo mismo ocurre también con ciertas normas morales que pueden receptarse por el derecho sin confundir la naturaleza de ambos órdenes normativos.

Con todo, los dilemas derivados de los regímenes totalitarios que campearon en el mediodía del siglo pasado, impusieron la necesidad de reposicionar la función del derecho como medio para lograr el respeto de los derechos fundamentales de las personas. Así aparecieron las cons-

de las otras normas del conjunto, con excepción de cuando menos una, la cual no autoriza la creación de ninguna norma; y (2) la creación de cada una de ellas está autorizada precisamente por una norma de ese conjunto, con excepción de una norma cuya creación no se encuentra autorizada por ninguna norma de la cadena. RAz, Joseph (2011), El concepto de sistema jurídico, trad. Rolando Tamayo y Salmorán, México, Ediciones Coyoacán, p. 128.

9 Para los efectos de este estudio basta con hacer esta referencia a la construcción escalonada del ordenamiento jurídico, sin tener que entrar a las distinciones que la teoría de Kelsen formuló sobre la naturaleza de la norma hipotética fundamental. Sobre ello, Kelsen, Hans, op. cit. nota 5, pp. 200 y siguientes.

${ }^{10}$ Kelsen, Hans, op. cit. nota 5, p. 202. 
tituciones rematerializadas a partir de la inclusión de densos catálogos de derechos, concebidos como exigencias colocadas por encima de los vaivenes de la voluntad mayoritaria. Sin embargo, el recurso de los derechos atrincherados no está completo si no se establece un sistema para garantizar que la Constitución sea respetada en todo tiempo por los actores públicos y privados. Tal sistema no necesariamente debe llevarnos a las puertas de la solución judicialista; sin embargo, en los hechos el constitucionalismo está acompañado de un novedoso modelo en relación con la judicatura. En la medida en que el jurista no sólo debe ocuparse de la descripción avalorativa de su objeto, sino que también debe atender a la crítica interna del derecho, es que estamos frente a un abandono creciente en la forma en que se concibe la función tradicional del juez como mera boca de la ley.

Después de la segunda mitad del siglo pasado comienzan a aparecer ordenamientos constitucionales que no solamente se contentan con organizar el poder público, sino que ahora ponen el acento en una reivindicación de la dignidad humana como precondición de existencia del estado y, desde luego, en la necesidad de imponer coactivamente la observancia de ciertos valores que dan identidad propia al ordenamiento jurídico. El estado constitucional se dota de constituciones largas, esto es, dotadas de sendos capítulos dedicados a reconocer derechos fundamentales a todos en cuanto dotados del estatus de personas, de ciudadanos o de personas con capacidad de obrar ${ }^{11}$. Pero además las normas constitucionales se caracterizan por ser enunciaciones demasiado amplias, lo que da lugar a que la posibilidad de conflictos entre derechos sea una constante en los ordenamientos. Las normas constitucionales están dotadas de una normatividad distinta a las del resto del ordenamiento, no sólo porque poseen una fuerza derogatoria irresistible, sino porque postulan un ejercicio hermenéutico diferente al de las reglas comunes. De esta manera parece quedar claro que la visión sustantiva de las normas fundamentales implica naturalmente un acercamiento entre la política y la judicatura; esto no puede ser de otra manera porque la Constitución no es otra cosa que la juridificación de la democracia ${ }^{12}$.

Naturalmente la cuestión fundamental en este caso será la de determinar las formas en las cuales se presentan las nuevas relaciones entre la magistratura, en especial de tipo constitucional, y los poderes públicos -ejecutivo y legislativo- que tienen una legitimación democrática directa de la cual carecen los jueces

\section{III. ¿La politización de la justicia o la judicialización de la política?}

Resulta incuestionable que el contenido de las normas constitucionales recuerda la expresión de los más caros ideales del hombre acuñados desde la más lejana historia ${ }^{13}$; pero también es incuestionable que éstos no pueden lograrse si no existe un régimen jurídico-político en donde la acción de las autoridades públicas se someta a rígidos límites predeterminados por las normas constitucionales. De este modo, podríamos explicar, por ejemplo, la aspiración del constituyente de 1917 para postular a la democracia como el único régimen de gobierno en el que tan excelso objetivo se puede lograr ${ }^{14}$; ello porque únicamente a través de este modelo pude construirse

\footnotetext{
${ }^{11}$ Ferrajoli, Luigi (2010), Derechos y garantías. La Ley del más débil, trad. de Perfecto Andrés Ibáñez y Andrea Greppi, $7^{\text {a }}$ ed. Madrid, Trotta, pp. 23-25.

12 Aragón Reyes, Manuel (2008), La constitución como paradigma, en Carbonell Sánchez, Miguel (compilador), Teoría de la constitución. Ensayos escogidos, $4^{a}$ edición, México, Porrúa- IIJ/UNAM, pp. 113 y 118.

13. Carpizo Mac-Gregor, Jorge (2002), La constitución mexicana de 1917, 13ª edición, México, Porrúa-IIJ/UNAM, p. 1.

14 Sobre el tema de la democracia en el constitucionalismo mexicano se puede consultar la obra de SánCHEz Bringas, Enrique (2009), Derecho constitucional, 12 a edición, México, Porrúa, pp. 444-466; donde el autor hace
} 
un un sistema de vida fundado en el constante mejoramiento económico, social y cultural del pueblo, según la expresión del artículo $3^{\circ}$ constitucional.

Sin embargo, la democracia mexicana atraviesa por un periodo de profunda legitimación en el ideario popular. A consecuencia de la transición política del estado mexicano se volvió inaplazable la consolidación del régimen democrático que asegure la gobernabilidad y el eficaz control del poder por medio de los mecanismos previstos para tal efecto. De aquí el papel protagónico que en lo sucesivo le corresponderá desempeñar al Poder Judicial de la Federación en general, y a la Suprema Corte de Justicia de la Nación en particular, como intérprete final de la constitución y garante del equilibrio entre los actores públicos. En efecto, por mucho tiempo la gran mayoría de los principios constitucionales elevados a la escala más importante del ordenamiento, tuvieron una existencia más aparente que real. Por ello, como bien afirma Zaldívar: la constitución se convirtió en instrumento del poder y no en norma jurídica para el control del ejercicio del poder ${ }^{15}$. Pero en la actualidad una nueva conformación de los factores sociales ha generado un creciente interés por el acontecer público, este fenómeno es la causa eficiente de un nuevo paradigma constitucional que obliga a tomar en serio las normas y principios de la ley fundamental. Esta nueva manera de entender la Constitución implica otorgarle su verdadero papel como centro gravitacional en la producción de todas las demás normas del sistema jurídico y como parámetro para calificar la legitimidad de toda la actuación de las autoridades. Pero no sólo ello. La Constitución se convierte en el marco de referencia dentro del cual deben tener expresión todas las opciones políticas y técnicas que tomen los legisladores u otros agentes de creación normativa ${ }^{16}$.

Esta nueva concepción de la Constitución como norma jurídica de contenido abierto, dada la pluralidad ideológica de la sociedad y sus representantes, exige que todos los conflictos que puedan surgir entre los agentes autoritarios adquieran la forma de auténticas controversias ventiladas y resueltas ante tribunales imparciales. A partir de lo anterior, el derecho constitucional se vuelve proceso para asegurar la aplicación de la norma suprema, de aquí la novedosa importancia de los tribunales encargados de velar por la observancia del código político y el papel fundamental que viene a desempeñar el derecho procesal constitucional dentro del contexto contemporáneo.

En la actualidad -como ya se adelantaba- la Suprema Corte se erige en el guardián supremo de la regularidad constitucional, lo cual ha evidenciado la necesidad de conocer en forma amplia y detallada los procesos intelectuales que llevan a determinar el sentido y alcance de los enunciados constitucionales y los procesos jurisdiccionales a través de los que se garantiza la sujeción a los mandatos primarios. En primer término, por lo que hace a la interpretación constitucional, es innegable que la reflexión sobre este tópico ha sido soslayada por la teoría nacional. No obstante ello, no puede desconocerse que la clarificación de los mandatos de la ley suprema supone un ejercicio hermenéutico parcialmente distinto del que se postula para la interpretación de las leyes ordinarias ${ }^{17}$. Lo anterior se debe a que los agentes de la interpretación son diversos a los que interpretan las demás leyes; a que las técnicas hermenéuticas son distintas

un interesante estudio de la idea democrática a lo largo de la historia hasta llegar a su conformación actual en la carta magna.

15 Zaldívar Lelo de Larrea, Arturo Fernando (2010), Hacia una nueva ley de amparo, $3^{\text {a }}$ edición, México, Porrúa-IIJ/UNAM, p. XX.

${ }^{16}$ Carbonell Sánchez, Miguel (2004), La constitución pendiente. Agenda mínima de reformas constitucionales, $2^{\text {a }}$ edición, México, IIJ/INAM, p. 1.

${ }^{17}$ Guastini, Riccardo (2006), Estudios sobre la interpretación jurídica, traducción de Marina Gascón y Miguel Carbonell, $2^{\text {a }}$ edición, México, Porrúa-IIJ/UNAM, p. 114. 
y a que los problemas de clarificación y aplicación del texto fundamental no son similares a los que se presentan para la fijación del sentido del resto de los preceptos jurídicos. Así las cosas, si asumimos que todos los conflictos en los que se debate la aplicación de una norma constitucional adquieren la forma jurídica de verdaderos procesos de control, será necesario conocer cómo se interpreta la carta magna por los jueces en sus sentencias, sobre todo en las que pueden determinar la inconstitucionalidad con efectos generales, como ocurre en el caso de la controversia constitucional y la acción de inconstitucionalidad.

En esto estriba la importancia de la actividad interpretativa de los tribunales de la federación, ya que como afirma José Ramón Cossío:

ocuparse hoy en día y en nuestro país del tema de la interpretación constitucional, es particularmente importante, pues la misma, por un lado habrá de cambiar de un modo notable y, por el otro, porque respecto de ella ha sido particularmente pobre la reflexión, como consecuencia los diversos actores politicos habrán de luchar por lograr que sus puntos de vista subjetivos se constituyan en sentidos normativos obligatorios, en lo futuro el modo en que se intérprete nuestra constitución será un asunto de mayor importancia, pues de ello dependerá que ciertas propuestas políticas y sociales sean consideradas como válidas y otras $n o^{18}$.

En lo que hace al papel de los jueces para controlar la actividad del resto de los poderes, la referencia puede ser muy prolija, aunque su estudio científico como un sector específico de la enciclopedia jurídica, puede fecharse en la célebre polémica entre Kelsen y Schmitt, sobre quién debe ser el defensor de la constitución. Veamos con relativo detenimiento la evolución de este fenómeno.

Desde la antigüedad se han desarrollado diversos instrumentos para controlar el ejercicio del poder; por ejemplo Tamayo y Salmorán recuerda que los reyes en Esparta eran dobles de manera que ambos pudieran ejercer una vigilancia reciproca para evitar los abusos de poder ${ }^{19}$. Al igual que acontecía en Esparta, las magistraturas republicanas en Roma tenían un carácter dual $^{20}$; con ello se evitaba que los magistrados cometieran excesos durante el desempeño de las actividades propias de estos importantes cargos. Más cercanos en el tiempo, puede decirse que el iusnaturalismo racionalista propio de la ilustración fue también la doctrina que sustentó la existencia inicial de los derechos fundamentales; así, tanto en la Declaración Universal de Derechos del Hombre y Ciudadano de 1789 -que serviría de inspiración para las constituciones francesas de 1791, 1793 y 1795- como en la constitución federal de los Estados Unidos de $1787^{21}$, se reiterará el reconocimiento y protección de los derechos humanos e inalienables de las personas, los cuales se conciben como la base de todas las instituciones sociales, cuyo respeto y

\footnotetext{
${ }^{18}$ Cossío Díaz, José Ramón (2004), citado por CARbonell SánChez, Miguel, Constitución, reforma constitucio-

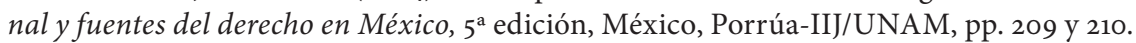

19 Tamayo Salmorán, Rolando (2003), Introducción al estadio de la constitución, $3^{\mathrm{a}}$ edición, México, Fontamara, pp. 19-34.

${ }^{20}$ Fix-Zamudio, Héctor y Valencia Carmona, Salvador (2003), Derecho constitucional mexicano y comparado, $3^{\text {a } e d i c i o ́ n, ~ M e ́ x i c o, ~ P o r r u ́ a-I I J / ~ U N A M, ~ p p . ~} 173$ y 174.

${ }^{21}$ Un interesante estudio de estos documentos puede consultarse en la obra de Hunt, Lynn (2009), La invención de los derechos humanos, traducción de Jordi Beltrán Ferrer, Tusquets, Barcelona.
} 
observancia constituyen exigencias que pueden imponerse inexorablemente a las autoridades en sus relaciones de imperio con los gobernados ${ }^{22}$.

Sin embargo, en realidad el primer antecedente plenamente formado que reivindicó el poder de los jueces para controlar los actos de los poderes ejecutivo y legislativo, se puede encontrar en la aportación norteamericana a la historia de la defensa constitucional: la judicial review. Este modelo fue desarrollado después de la promulgación de la constitución federal. En virtud de la revisión judicial los tribunales se hallan investidos de la competencia necesaria para revisar y, de ser el caso, invalidar por inconstitucionales los actos del poder ejecutivo y legislativo, así como de los órganos inferiores del poder judicial. A pesar de que este instrumento de control no estaba expresamente consignado en el texto de la constitución de 1787, fue un desarrollo jurisprudencial creado por la Corte Suprema a partir del famoso caso Marbury vs. Madison. En la parte fundamental de este celebérrimo fallo el presidente de la Corte, John Marshall, estableció que

o bien la constitución es la norma superior, que no puede ser modificada por medios ordinarios, o bien está al nivel de los actos legislativos y, como otros actos, se puede modificar cuando la legislatura lo desee. Si la primera alternativa es cierta, un acto legislativo contrario a la constitución no es una ley; si la segunda parte es cierta, entonces las constituciones escritas son intentos absurdos, de parte del pueblo, de limitar un poder que, por su propia naturaleza, no es limitable $^{23}$.

Aun con todo, no puede pasar inadvertido que el antecedente directo de la defensa judicial de la constitución -y con ello del acercamiento entre la magistratura y el poder político- se encuentra en la polémica suscitada a principios del siglo pasado ente el jurista alemán Carl Schmitt y el ilustre autor de la Teoría pura del derecho, Hans Kelsen. Para el primero de los nombrados la defensa de la carta fundamental debía confiarse a un órgano de carácter político, específicamente el presidente del Reich, con base en las facultades que le confería el artículo 48 de la constitución alemana de 1919. Para Schmitt el problema no podía resolverse de una manera distinta, ya que confiar la tutela de las normas supremas a los tribunales implicaría la judicialización de la política o la politización de la justicia, de suerte que cualesquiera de estas consecuencias eran indeseables. Por su parte, Kelsen defendía la naturaleza judicial del ente controlador de la constitucionalidad. De acuerdo a las ideas del reputado el autor austriaco, el órgano defensor del código político tendría que ser un tribunal investido de facultades distintas e independiente del poder judicial ordinario, el cual tuviera la competencia necesaria para expulsar del ordenamiento a las normas y actos jurídicos irregulares mediante una declaratoria con efectos generales, es decir, el tribunal constitucional cumpliría la labor de un legislador negativo al realizar una función depuradora del sistema, a través de la expulsión de las normas $\mathrm{y}$ actos que resultaran contrarios a la regla de reconocimiento del propio orden.

En realidad, parece que el modelo kelseniano, que confía la defensa de la Constitución a un tribunal especializado, terminó por imponerse incluso de forma más intensa de la que el propio autor lo hubiera pensado, porque en la actualidad los jueces constitucionales no solamente actúan como legisladores negativos, sino que en realidad se han abocado a completar y perfeccionar la obra del legislador democráticamente elegido. Desde luego, este hecho plantea un dilema en torno a la legitimidad de la jurisdicción constitucional -de lo cual me ocuparé en el

\footnotetext{
${ }^{22}$ Fix Zamudio, Héctor y Ferrer Mac-Gregor Poisot, Eduardo (2011), Derecho de amparo, México, Porrúa-IIJ/ UNAM, p. 12.

${ }^{23}$ El fragmento de la sentencia está tomado de Carbonell Sánchez, Miguel (2008), Marbury versus Madison: regreso a la leyenda, en ¿Tercero ausente? Ensayos sobre el poder judicial, México, Porrúa-IMDPC, p. 7.
} 
parágrafo VI-. Por ahora pasaré a exponer hasta qué grado la Suprema Corte de Justicia participa de este acercamiento con el sector político al ocuparse del control jurídico de la actividad de los demás poderes públicos, para lo cual nos tendremos que ocupar del carácter de tribunal constitucional que actualmente ostenta nuestro más alto colegio judicial.

\section{La Suprema Corte como Tribunal Constitucional}

El control judicial de constitucionalidad como el propuesto por Kelsen, se caracteriza por la creación de órganos especializados en la resolución de los conflictos derivados de la aplicación de la preceptiva fundamental. En este orden de ideas, el tribunal constitucional puede ser definido de acuerdo a las palabras de Ferrer Mac-Gregor, en el sentido siguiente:

Entendemos por Tribunal Constitucional a los altos órganos judiciales o jurisdiccionales, situados dentro o fuera del Poder Judicial, independientemente de su denominación, cuya función material esencialmente consista en la resolución de los litigios o conflictos derivados de la interpretación o aplicación directa de la normativa constitucional ${ }^{24}$.

De esta guisa, las cortes constitucionales pueden merecer tales calificativos desde dos perspectivas diversas:

Formalmente serán tales los organismos colocados fuera del Poder Judicial, que resuelven de manera exclusiva las controversias de carácter constitucional -como era el caso de la Alta Corte Constitucional Austriaca ideada por Kelsen.

En tanto que materialmente se califican de tribunales constitucionales a los entes de mayor jerarquía dentro de la estructura orgánica del poder judicial, que poseen la función exclusiva o esencial de establecer la interpretación y sentido final de las disposiciones de carácter constitucional $^{25}$.

En sentido material, queda claro que la Suprema Corte de Justicia de la Nación se configura como un auténtico tribunal constitucional, sobre todo a partir de las reformas de 1988, 1994 y 1996. En la reforma constitucional de 1994 se puede advertir que la tendencia del constituyente permanente ha sido la de configurar a la Suprema Corte de Justicia de la Nación como un tribunal materialmente constitucional, al desplazar la mayoría de los asuntos de control de legalidad a los Tribunales Colegiados de Circuito, los cuales incluso tienen competencia para conocer asuntos en los que se debatan cuestiones netamente constitucionales siempre que el más Alto Tribunal ya haya sentado jurisprudencia sobre el tema. Así, la Suprema Corte conserva para su resolución únicamente los juicios de amparo en los que por su importancia y trascendencia haya de fijarse un criterio de relevancia para el orden jurídico nacional, o bien, los juicios constitucionales directos en revisión, cuando se haya interpretado un artículo de la Constitución. Además, después de la reforma constitucional aludida, se agregó la competencia para que la Suprema Corte conociera de las acciones de inconstitucionalidad, previstas por la fracción II del artículo 105 constitucional, aunado a un nuevo régimen jurídico de las controversias a que

\footnotetext{
${ }^{24}$ Fix Zamudio, Héctor y Ferrer Mac-Gregor Poisot, Eduardo, op.e cit. nota 20, p. 67.

${ }^{25}$ Fix-Zamudio, Héctor (2001), voz: tribunales constitucionales en Nuevo diccionario jurídico mexicano, PorrúaIIJ/ UNAM, tomo P-Z, p. 3804.
} 
se refiere la fracción I del mismo numeral, ello mediante la ampliación de los supuestos de procedencia de este tipo de procesos propios de la justicia constitucional.

Evidentemente cuando la Suprema Corte de Justicia ejercita sus competencias en materia de control de constitucionalidad hace uso de funciones muy diferentes a las que supone el conocimiento de los negocios de jurisdicción ordinaria -como podría ser el conocimiento de una apelación en un juicio en el que la Federación sea parte- porque en ellos la Corte entra de lleno al ejercicio de funciones jurisdiccionales de corte político en la medida en que la principal función en este caso es el control de los poderes públicos. Como es natural, esta actividad se ha confiado al poder judicial luego de que se ha constatado que el parlamento también puede ser fuente de opresión y participe de la tiranía, por lo que es necesario que los jueces velen por el respeto de la constitución, pues ella materializa a la ley suprema que vincula a todas las autoridades, incluido el poder legislativo, por ello los últimos garantes de la supremacía de la constitución son los jueces que determinan el sentido y alcance de sus preceptos y reprimen el incumplimiento de los mandatos constitucionales. Con base en las consideraciones que he vertido a lo largo de este apartado, es claro que la Corte ha adquirido definitivamente el carácter de supremo defensor de la constitucionalidad en el ordenamiento mexicano y por esto mismo ha acentuado su carácter de tribunal constitucional.

\section{Las influencias de la política en la función judicial}

Prácticamente desde la publicación de la constitución de 1917 y hasta que el partido hegemónico perdió la mayoría en el Congreso de la Unión, el Poder Judicial Federal y en especial la Suprema Corte de Justicia de la Nación, vivió épocas de profunda inestabilidad. Este hecho se debió en parte a factores extralegales, como el hecho de que el presidente de la república ejercitaba poderes metaconstitucionales ${ }^{26}$, en relación por ejemplo a la designación de los funcionarios en general; y en particular por una serie de factores originados en las constantes modificaciones a la composición de la Suprema Corte, así como por una excesiva mutabilidad de las leyes orgánicas y procesales que le otorgaban competencias al más alto colegio jurisdiccional de país. De acuerdo con Ansolabehere es posible identificar tres periodos de cambios institucionales impresos por el gobierno en turno a la Suprema Corte ${ }^{27}$ :

El primero relativo a la configuración del papel del poder judicial federal con el poder político representado por el ejecutivo, en el cual cada uno de los presidentes de la república trató de incidir directamente en la Corte a través de la designación y determinación del número y duración en el cargo de sus integrantes.

El segundo que se refiere a una jerarquización de la Corte respecto del resto de los órganos conformadores del poder judicial, lo que implicó una reasignación de sus atribuciones para convertirla en un auténtico tribunal de casación, encargado de preservar la legalidad de la actuación de todos los tribunales sufragáneos y de la administración de justicia en general.

En tanto que en el tercer periodo se opera una especie de refundación de la Suprema Corte con el poder político, lo que implicó -desde 1994 y hasta la fecha- fortalecer el carácter de tri-

\footnotetext{
26. CARPizo Mag-Gregor, Jorge, op. cit. nota 12, p. 239.

27 Asonlabehere, Karina (2006), La política desde la justicia. Cortes supremas, gobierno y democracia en México y Argentina, México, FLACSO-Fontamara, pp. 95-160.
} 
bunal constitucional y la concentración de cierta clase de procedimientos de control de constitucionalidad que pueden producir sentencias anulatorias con efectos erga omnes.

Lo cierto es que las relaciones del poder judicial con el poder público, al menos en los dos primeros periodos descritos no supuso un vínculo tirante, sino que más bien describe los términos de una relación condescendiente del poder judicial con el ejecutivo. En principio, porque la independencia de los magistrados de la Corte podía sostenerse en términos apenas ilusorios, como lo demuestran las constantes modificaciones en la integración del alto tribunal y las frecuentes reformas a la extensión de los periodos de los ministros y las enmiendas a las leyes que regían la función judicial. Sobre este aspecto José Ramón Cossío ha observado que el hecho de que la Suprema Corte no haya desarrollado una teoría constitucional, se debe en parte a una especial concepción de la constitución. En realidad en los dos primeros periodos descritos la carta magna no se concebía como una autentica norma jurídica, sino como una especie de programa político que reflejaba el ideario del partido surgido de la revolución ${ }^{28}$. Si esto es así, entonces la norma suprema no era directamente aplicable por los tribunales, y, por tanto, tampoco podía invocarse como un criterio para determinar la contradicción de alguna acción gubernamental con la norma suprema.

Al menos hasta antes de las reformas de 1994, que ampliaron las competencias de la Suprema Corte al hacer plenamente efectiva la regulación de las controversias constitucionales y la creación de las acciones de inconstitucionalidad, el poder judicial de la federación no se apartó del clásico paradigma difundido desde tiempos de Montesquieu, en el sentido de que el juez es sólo la boca de la ley. Sin embargo, también debemos reconocer que actualmente este no parece ser del todo el modelo que describa el papel de la Suprema Corte de los últimos veinte años.

Frente a una magistratura cada vez más activa y consiente de su papel, el poder ejecutivo ha perdido influencia sobre la actividad de la Suprema Corte en la medida en que el alto tribunal ha reivindicado para sí espacios en los cuales la actividad judicial independiente es necesaria ${ }^{29}$. Si se hace un análisis de las resoluciones pronunciadas por la Suprema Corte al resolver los mecanismos de control propios de la jurisdicción constitucional orgánica ${ }^{30}$, esto es, en los cuales el alto tribunal debe pronunciarse sobre un conflicto de atribución de competencias entre poderes y puede producir un fallo anulatorio con efectos generales; se advierte que si el presidente durante su sexenio no interviene en la designación de los integrantes del colegio judicial, se incrementa la posibilidad de que los litigios sean resueltos en sentido contrario a las pretensiones del ejecutivo. También se elevan las posibilidades de sentencias contrarias al presidente en turno, cuando la materia de la impugnación tiene que ver con procesos legislativos a través de los cua-

\footnotetext{
${ }^{28}$ Cossío Díaz, José Ramón (2010), La teoría constitucional de la Suprema Corte de Justicia, $2^{\text {a }}$ edición, México, Fantamara.

${ }^{29}$ En esta parte seguiremos de cerca el trabajo de Cortez SAlinas, Josafat (2015), Análisis cualitativo comparado: las decisiones de la Suprema Corte contra el ejecutivo en México, en Revista Mexicana de Sociología No. 76, julioseptiembre, pp. 413-439.

${ }^{30}$ Ibídem, p. 417, pasim.
} 
les el ejecutivo quiere imprimir su sello a las políticas públicas o se trata de acotar las funciones presidenciales y distribuir el poder.

La conclusión anterior evidencia que la Corte mexicana ha en serio la tarea de controlar al resto de los poderes de la Unión, aunque con alguna deferencia hacia el legislativo en lo que hace a la calificación de inconstitucionalidad de la ley, al menos por dos causas:

Primero por una especie de presunción de constitucionalidad de la ley, derivada de que el legislativo representa en toda su extensión el principio democrático, legitimación que en el caso del poder judicial se haya más difuminada.

Y porque existe una autolimitación en el ejercicio de los poderes de anulación del juez constitucional, a fin de mantener una relación estable con el resto de los poderes, especialmente con el legislativo.

Por ello el interés por la actividad judicial de la Suprema Corte se ha acrecentado a partir de la fragmentación del poder político y de que el presidente en turno no ha nombrado a la mayoría de los jueces constitucionales, lo que supone la necesidad de describir la forma en que las cortes supremas deciden con base en sus precedentes, las actitudes y preferencias políticas de sus miembros o con base a criterios racionales limitados por la estrategia, las preferencias personales y el contexto institucional; pero fundamentalmente porque los tribunales constitucionales son el nuevo foro donde se da cita el debate más articulado en torno al proyecto constitucional en pos de la democracia y el estado de derecho.

Pero además las relaciones del poder judicial con el poder político se han intensificado en el contexto del estado moderno en la medida en que el poder judicial ha servido mejor que otros poderes para procesar las demandas de la población, por ello en parte se ha abandonado la concepción mecánica de la aplicación de la ley. Un elemento en donde puede advertirse con mayor claridad este fenómeno es el campo de los derechos sociales, pues dentro del estado constitucional se ha verificado una espectacular expansión de las prestaciones esenciales para las personas, otorgadas por el estado en áreas que el liberalismo dejaba en manos de la acción de los particulares. En este sentido:

Queda claro que las fronteras entre la jurisdicción, la legislación y la administración tienen a borrarse. El hecho de que el juez sea también un legislador se considera ya hoy como una obvia banalidad. Los ámbitos de discrecionalidad de que dispone y las mismas características del procedimiento de decisión le llevan de hecho a participar en la formulación de las políticas públicas $^{31}$.

Sin embargo, aunque las relaciones entre la magistratura y la política sean una cuestión evidente, queda todavía un problema por considerar, pues el poder judicial carece de una legitimación democrática directa para anular los actos del poder legislativo o ejecutivo, los cuales se legitiman en su elección y acciones a través del sufragio popular.

\section{VI. ¿De camino al gobierno de los jueces?}

El constitucionalismo encierra una tesis a favor de los derechos y un compromiso con la idea de la democracia. En efecto, el constitucionalismo debe resolver la pregunta de por qué en una democracia existen cartas de derechos que no pueden ser tocadas por la mayoría y, adicional-

\footnotetext{
${ }^{31}$ Guarnieri, Carlo y Pederzoli, Patrizia (2009), Jueces y política, Madrid, Taurus, pp. 15-30 y 127-161.
} 
mente, la rama judicial tiene el poder de anular las leyes del congreso y los actos de la administración. La existencia de cartas de derechos que los poderes judiciales deben salvaguardar es expresión de la dimensión sustancial de la democracia. En esta medida las facultades de anulación del poder judicial se pueden justificar en una especie de idea del pre-compromiso al modo de Ulises, pues es el propio pueblo el que decide atarse las manos para no reformar en el futuro sus constituciones para restringir esos derechos, al tiempo que se confía la tarea de tutela de tales declaraciones al poder judicial. Precisamente para que las constituciones puedan ser lo más longevas posible es que a sus contenidos se les da una formulación abstracta y principialista, que provee el margen suficiente para el debate sobre los derechos y los temas de relevancia social siempre dentro de los espacios constitucionalmente previstos.

Pero las líneas más interesantes del debate se articulan en torno a la defensa o crítica de la revisión judicial de la ley. Por los apretados límites de este trabajo no podremos detenernos demasiado en dicha cuestión, sino sólo avanzar una especie de bosquejo de sus lineamientos generales. Para abordar esta parte primero nos referiremos a los argumentos ortodoxos del Kelsen para legitimar a la justicia constitucional; luego estudiaremos la postura de Robert Alexy quien plantea la posibilidad de una defensa argumental de la magistratura constitucional. Y finalmente nos centraremos en el debate en torno a la legitimidad de la justicia constitucional que ha encontrado en Ronald Dworkin a uno de sus más esclarecidos defensores, en tanto que ha topado en Jeremy Waldron con uno de sus más descarnados críticos.

La justificación de Kelsen sobre la legitimidad democrática del tribunal constitucional, que pese a haber perdido su fuerza persuasiva original, no debe ser inadvertido porque se ubica en el origen mismo del desarrollo del derecho procesal constitucional. Como adelantamos, para Kelsen la discusión sobre la legitimidad de la justicia constitucional es un asunto que debe darse por descontado, en la medida en que se trata de una función propia de un legislador negativo, cuya única misión es depurar el ordenamiento jurídico. De esta manera, para el ilustre pensador austriaco, la función legislativa encuéntrase dividida en dos partes, la positiva que consiste en la facultad de creación normativa depositada en el parlamento; y la potestad de legislación negativa que reside en el tribunal constitucional. Bajo esta premisa la objeción democrática parece diluirse ${ }^{32}$. Faltaría, sin embargo, evaluar hasta dónde las críticas vuelven a tomar fuerza cuando el tribunal se aparta de la simple anulación e innova el ordenamiento, mediante sentencias que producen efectos distintos a la expulsión de la norma.

Más interesante, tal vez por actual, es la tesis del reputado profesor de Kiel, Robert Alexy. En términos que retoman en parte los de Dworkin y John Rawls, el autor de la Teoría de los derechos fundamentales sostiene que el tribunal constitucional que intente resolver de manera adecuada a las objeciones democráticas, no

\footnotetext{
${ }^{32}$ Kelsen, Hans, La garantía jurisdiccional de la constitución (La justicia constitucional), op. cit. nota 2, pp. 54-55.
} 
pretenderá situar su concepción en contra de la del legislador, sino que más bien aspirará a una representación argumentativa de los ciudadanos, por oposición a su representación política en el parlamento. Cuando triunfa la representación argumentativa, triunfa la reconciliación $n^{33}$.

De suerte que será la calidad argumentativa de las sentencias constitucionales la que en última instancia aportará el criterio cualitativo para legitimar la tarea del juez constitucional.

Pasemos ahora a los términos del debate Dworkin-Waldron sobre la legitimidad de la justicia constitucional $^{34}$.

El argumento central de la defensa de Dworkin consiste en destacar la forma del razonamiento judicial basado en principios, ya que considera que éstos protegen de mejor forma las condiciones del juego democrático, en virtud de que la revisión judicial implica un tipo superior de deliberación republicana. Frente a las afirmaciones del autor de El imperio de la justicia, Waldron sostiene que no siempre los jueces razonan conforme a principios morales y que comúnmente las sentencias pierden de foco el esclarecimiento de los temas verdaderamente importantes para la sociedad. Sigue diciendo Waldron, que los jueces, especialmente los constitucionales, no siempre están en el mejor lugar para advertir los problemas sensibles de las personas, ya que por regla general a las cortes supremas llegan los problemas desvinculados de las condiciones de hecho que les dieron origen. El crítico de Dworkin sostiene entonces que los legisladores también pueden argumentar con calidad y suficiencia las elecciones que realizan al formular una ley. De esta suerte, concluye que si nos preguntamos por qué las cortes constitucionales están mejor posicionadas para juzgar la conformidad de las leyes con la constitución, en ningún caso podríamos aportar argumentos concluyentes, pues es al poder legislativo a quien debería corresponderle la última palabra sobre esta materia.

Tanto la defensa esbozada por Ronald Dworkin como la crítica que le formula Jeremy Waldron pueden calificarse de generales en la medida en que tienen a ser aplicables a cualquier sistema de control judicial de la constitucionalidad. Sin embargo, es posible todavía revisar un frente más de defensa de la justicia constitucional, que puede ser llamado argumento contextual, ya que dependerá de las circunstancias concretas en las cuales se realiza el control judicial de constitucionalidad.

Esta defensa contextual del control de la regularidad constitucional en manos de los jueces supone que ésta queda legitimada en tres casos específicos, a saber:

En el supuesto de sociedades fracturadas, es decir aquellas que atraviesan por profundos conflictos sociales o que no comparten un interés común.

En el caso de las democracias nuevas o en periodo de consolidación en las que no existe una sociedad civil comprometida con la supervivencia de las instituciones políticas.

Y finalmente, en las sociedades marcadas por la desigualdad y la pobreza, en donde amplios sectores de la población no tienen acceso a las mismas oportunidades de desarrollo.

En síntesis, los argumentos de la defensa contextual de la jurisdicción constitucional, no tienen el peso suficiente para legitimar el papel activo de la magistratura dentro del estado contemporáneo. Esto es así porque si dadas las condiciones descritas el poder legislativo no garantiza las condiciones de estabilidad que permitan el juego democrático, por identidad de razón,

\footnotetext{
33. AleXy, Robert (2009), Los derechos fundamentales en el estado constitucional democrático en CARBONELL SáNCHez, Miguel (editor), Neoconstitucionalismo(s), $4^{\text {a }}$ edición, Madrid, Trotta, p. 40.

34. En esta parte seguiremos de cerca la exposición que se hace en el trabajo de Linares Lejarraga, Sebastián (2008), La (i)legitimidad democrática del control judicial de las leyes, Madrid, Marcial Pons, pp. 45-98.
} 
no existe ningún fundamento plausible para considerar que los jueces asuman el papel redentor que la defensa contextual les asigna.

\section{A manera de conclusión}

En estas líneas he querido mostrar que en la actualidad no puede sostenerse el modelo decimonónico de la función judicial, circunscrito sólo a la subsunción de los casos concretos en las normas generales; en parte porque la aplicación del derecho nunca ha sido una operación puramente lógica, y en parte porque los modernos sistemas jurídicos dotados de constituciones largas, son conjuntos mucho más complejos de disposiciones de conducta. Ello ha ocasionado el interesante fenómeno que ha conducido a otorgar al poder judicial un rol protagónico, no se quiere decir con ello que el poder judicial antes no fuera uno de los llamados tres poderes de la Unión, sino que en la medida en que la Suprema Corte se ha separado de las influencias directas del resto de los poderes y ha ganado mayores espacios de autonomía, es que ha podido convertirse en un auténtico contrapeso y en un ente controlador de los actos de los demás agentes del poder público. Naturalmente este nuevo papel de los jueces describe un proceso en formación respecto del cual pueden formularse serias críticas y que incluso puede verse con una suerte de desconfianza, derivado sobre todo de la objeción contramayoritaria de las cortes constitucionales. Sin embargo, creemos que esta es una tendencia natural de los estados contemporáneos caracterizados por la pluralidad de formas de pensar y de otras tantas opciones políticas. En lo particular, nos parece que el temido gobierno de los jueces no es más que la exageración de los naturales márgenes de discrecionalidad de que siempre ha gozado la magistratura. Aunque el poder judicial adquiere mayor peso, lo cierto es que este poder también se halla limitado, al menos por los siguientes factores:

Por la instancia de parte, en la medida en que el control judicial siempre requiere de la solicitud expresa del interesado.

El juez está sujeto al derecho -normas y precedentes- que existen antes de la resolución del caso concreto.

Los tribunales siempre deben escuchar las pretensiones de las partes procesales y resolver únicamente con base en las pretensiones deducidas en el juicio.

Y finalmente, en todos los casos debe motivar el sentido de sus resoluciones, es decir, la función extraprocesal de la motivación de la sentencia.

Cuestiones como estas, desde luego, permiten mantener dentro de los márgenes de racionalidad y proporcionalidad la actividad novedosa y protagónica de las cortes constitucionales. Lo cual no significa que la polémica sobre la legitimación de la justicia constitucional pueda razón de ser, sino que, por el contrario, nos permite centrar las coordenadas de un debate por demás importante en el momento actual. En todo caso, en este breve estudio hemos querido dejar clara una cosa: si aceptamos los presupuestos del estado constitucional, no podemos extrañarnos de sus consecuencias, una de las cuales, tal vez la más importante, es el novedoso e importante papel que le corresponde desempeñar a las cortes constitucionales en la construcción del estado de derecho.

\section{Fuentes empleadas}

Alexy, Robert (2005), Derecho y moral, en Ferrer Mac-Gregor, Eduardo (coordinador) Interpretación constitucional, México, Porrúa-IIJ/UNAM. 
, Los derechos fundamentales en el estado constitucional democrático en CARBONELL, Miguel (2009), (editor), Neoconstitucionalismo(s), 4 a edición, Madrid, Trotta.

Aragón Reyes, Manuel (2008), La constitución como paradigma, en CARbonell Sánchez, Miguel (compilador), Teoría de la constitución. Ensayos escogidos, $4^{\mathrm{a}}$ edición, México, Porrúa- IIJ/UNAM, pp. 113 y 118.

Asonla behere, Karina (2006), La política desde la justicia. Cortes supremas, gobierno y democracia en México y Argentina, México, FLACSO-Fontamara.

Carbonell Sánchez, Miguel (2008), ¿Tercero ausente? Ensayos sobre el poder judicial, México, Porrúa-Instituto Mexicano de Derecho Procesal Constitucional.

, Constitución, reforma constitucional y fuentes del derecho en México, $5^{\mathrm{a}}$ edición, México, Porrúa-IIJ/UNAM 2004.

,La constitución pendiente. Agenda mínima de reformas constitucionales, $2^{\mathrm{a}}$ edición, México, IIJ/INAM, 2004.

Carpizo Mac-Gregor, Jorge (2002), La constitución mexicana de 1917, 13ª edición, México, Porrúa-IIJ/UNAM.

Cortez Salinas, Josafat (2015), Análisis cualitativo comparado: las decisiones de la Suprema Corte contra el ejecutivo en México, en Revista Mexicana de Sociología No. 76, julioseptiembre.

Cossío DíAz, José Ramón (2010), La teoría constitucional de la Suprema Corte de Justicia, $2^{\mathrm{a}}$ edición, México, Fantamara.

Cossío DíAz, José Ramón (2013), Sistemas y modelos de control constitucional en México, $2^{\mathrm{a}}$ edición, México, IIJ/UNAM.

Ferrajoli, Luigi (2010), Derechos y garantías. La Ley del más débil, trad. de Perfecto Andrés IвÁÑEZ y Andrea GrePpI, $7^{\mathrm{a}}$ ed., Madrid, Trotta.

Fix Zamudio, Héctor y Ferrer Mac-Gregor Poisot, Eduardo (2011), Derecho de amparo, $1^{\mathrm{a}}$ edición, México, Porrúa-IIJ/ UNAM.

, y Valencia Carmona, Salvador (2003), Derecho constitucional mexicano y comparado, $3^{\text {a }}$ edición, México, Porrúa-IIJ/ UNAM.

Guarnieri, Carlo y Pederzoli, Patrizia (2009), Jueces y política, Madrid, Taurus.

Guastini, Riccardo (2006), Estudios sobre la interpretación jurídica, traducción de Marina Gascón y Miguel Carbonell, $2^{\text {a }}$ edición, México, Porrúa-IIJ/UNAM.

Hunt, Lynn (2009), La invención de los derechos humanos, traducción de Jordi Beltrán FERrer, Tusquets, Barcelona. 
Kelsen, Hans (2001), La garantía jurisdiccional de la constitución (La justicia constitucional), trad. de Rolando Tamayo y Salmorán, México, IIJ-UNAM.

Teoría pura del derecho, trad. Moisés Nilve (2012), $3^{\text {a }}$ edición, México, Ediciones Coyoacán, 2012.

Linares Lejarraga, Sebastián (2008), La (i)legitimidad democrática del control judicial de las leyes, Madrid, Marcial Pons.

Mora Sifuentes, Francisco M (2017), La influencia de los derechos fundamentales en el ordenamiento. Su dimensión objetiva, en Boletín Mexicano de Derecho Comparado, No. 150, México, IIJ/UNAM.

Raz, Joseph (2011), El concepto de sistema jurídico, trad. Rolando Tamayo y Salmorán, México, Ediciones Coyoacán.

Rodríguez Durón, Everardo (2017), El control constitucional ante el desafío democrático. Un acercamiento al problema contramayoritario en el derecho constitucional mexicano, Tesis para obtener el grado de Maestro en Justicia Constitucional, Universidad de Guanajuato, Guanajuato.

SÁnchez Bringas, Enrique (2009), Derecho constitucional, $12^{\mathrm{a}}$ edición, México, Porrúa.

Tamayo Salmorán, Rolando (2003), Introducción al estadio de la constitución, $3^{\text {a }}$ edición, México, Fontamara.

Tusseau, Guillaume (2011), Para acabar con los modelos de jurisdicción constitucional. Un ensayo de crítica, trad. de Teresa García Berrio, México, Porrúa-IMDPC.

Zaldívar Lelo De Larrea, Arturo Fernando (2010), Hacia una nueva ley de amparo, $3^{\mathrm{a}}$ edición, México, Porrúa-IIJ/UNAM. 